\title{
Factors Influencing Contraceptives Use among Female Migrants in Ghanaian Cities, A case of Kayeyei in the Kumasi Metropolis
}

\author{
Cynthia Avoada \\ Department of Geography and Rural Development, \\ Kwame Nkrumah University \\ avoadacynthia06@gmail.com \\ Dorigen Ansomaa Asumadu \\ Department of Geography and Rural Development, \\ Kwame Nkrumah University \\ doriasumadu@gmail.com \\ Bismark Affreh Junior \\ Department of Geography and Rural Development, \\ Kwame Nkrumah University \\ abismark288@yahoo.com

\section{Moses Ackah Anlimachie} \\ Education Futures, University of South Australia, Adelaide, Australia \\ http://orcid.org/0000-0001-5319-5524 \\ moses.anlimachie@mymail.unisa.edu.au
}

\begin{abstract}
Historically, women in Africa have long been known to transport agricultural produce, firewood, and pots of water by way of the head for domestic use. This culture has been transformed into feminised unskilled labour termed Kayayei in Ghanaian cities as a fallout from poor education outcomes and its attendant lack of sustainable jobs in the rural areas. Kayayei is used in Ghana to refer to young female migrants between the ages of 8-35 years from the poverty endemic areas of northern Ghana engaging in head porterage business in the cities as a means of survival. The increasing incidence of kayaye and its attendant social, health and economic problems have attracted media and research commentary in Ghana in recent times. This study investigates contraceptive use among kayayei in the Kumasi metropolis of Ghana to inform strategies to improve the reproductive health of the lowincome group. The study uses a mixed-method design. A structured survey questionnaire was administered to 121 kayayei. Further, 44 participants were selected from the 121 kayeyei to participate in focus group discussions (FGD). These were complemented with individual interviews of a pharmacist, a chemist shop attendants, and a drug peddler [unlicensed medicine walker]. Statistical Package for Social Sciences (SPSS) was used to analyse the quantitative data from the survey questionnaire, while descriptive coding was used to analyse
\end{abstract}


the qualitative data from FGDs, interviews and field observation. The findings revealed that male partners' approval was the major determinant of contraceptive use among the participating migrant female head porters. Some $90 \%$ of women who were less likely to use contraceptives are those who never discuss or get approval from their partners. Oral contraceptives, intrauterine devices (IUD) and condoms were the most used contraceptive among the kayayei. Participants' choice of contraceptives was influenced by affordability, accessibility and their perceptions about contraceptive security. The study also identified that side effects from the use of contraceptives, including inconveniences on menstruation, weight gain, and weight loss, were a set of factors that demotivate contraceptives use among the research participants. The study also identified that, although culture has a significant influence on contraceptive use in Africa generally, in the case of migrant young women who have escaped from the cultural scrutiny of their home communities, their sexual partners, rather than culture, have a significant influence on their contraceptives use. The study, therefore, recommends an aggressive public education campaign on contraceptives use targeting both kayayei and their sexual partners in Ghanaian cities, while family planning services are accessible and affordable to this low-income group.

Keywords: contraceptives use; migrant women; head porters; health wellbeing; low-income group

\section{Introduction}

The use of contraceptives is a globally acclaimed strategy to control rapid population growth to create sustainable communities. Contraception or fertility control, deliberate use of practices, drugs, surgical procedures to forestall physiological conditions from occurring in sexually active persons have been growing in the post-World War Two era (Darroch et al., 2011). At the family level, contraception is used to prevent unplanned pregnancies and to control family size and its attendant dependency burden. The use of contraceptives is also meant to prevent unsafe abortion, maternal mortality and morbidity. At the national level, contraceptives use serves as a strategy for population control, poverty reduction, and health, education planning geared towards individual and community wellbeing (Cleland et al., 2006).

The positives of contraceptive use have not been fully leveraged in Africa, accounting for the high dependency burden and poverty. Utilisation of family planning in sub-Saharan Africa is the lowest compared to other regions, with about under $20 \%$ utilisation. A survey conducted by the National Population Commission (2014) found that only $10 \%$ of sexually active women use modern contraceptives in Nigeria. In Ghana, the high fertility rate $(3.9 \%)$ suggests a low contraceptive utilisation linked to low education and socioeconomic status (Ghana and Demographic Survey Health- GDHS, 2015).

In Africa, negative traditional cultural practices like forced and early marriages, and female genital mutilation, among others, together with the quest for economic survival and poor education outcomes and opportunities are increasingly forcing many young women to migrate from the rural to the urban areas (Amoako-Mensah et al. , 2019; Anlimachie, 2016; Tomasevski, 2005). These young women are mostly poorly educated hence their skills do not match with urban jobs; they thus resort to menial jobs like head porting for economic survival. Such young women live in mi-shift structures and on the streets with poor access to health information, exposing them to the vagaries of social vices and reproductive health risks. (Amoako-Mensah et al., 2019; Anlimachie, 2016, 2019; Carter et al., 2020) 
Although women account for nearly half of migration globally (Bonifacio, 2012), analysis of the relationship between young females' migration and their family health wellbeing has little attention in the contemporary literature compared to rural-urban migration and NorthSouth transmigration (Bonifacio, 2012). In Ghana, every year young females between the ages of 12 to 35 years old migrate, either seasonally or semi-permanently, from rural and poverty endemic areas in the north of the country to the major cities or market centres, for menial jobs, mostly head porterage (kayayei). Most of these young ladies live in the streets or mi-shift or temporary structures in or close to key market centres in the cities. They are thus exposed to elicit sex, sexual abuse and other social vices (Opare, 2003; Shamsu-Deen, 2013). The kayayei phenomenon and its associated health, social and economic problems are increasingly becoming an albatross in Ghana and need holistic long to medium-term development and poverty reduction strategies. But meanwhile how does Ghanaian society improve the reproductive health of this socioeconomic disadvantaged group to reduce the increasing birth rate and sexual transmission of disease among this disadvantaged group? This study sought to investigate the factors that influence contraceptive use among migrant kayayei [young women head porters] in the Kumasi Metropolis of Ghana. The study deepens understanding on contraceptive use among low socioeconomic status migrant women while creating awareness of the best strategies to meet the reproductive health wellbeing of such vulnerable groups. The study informs health practitioners on the best way to reach out and the strategies to respond to the reproductive health needs among these socioeconomically marginalised young women.

The key research questions under investigation are:

1. What knowledge base do migrant female head potters have on contraceptives?

2. What are the patterns and usage of contraceptives among the migrant female head porters?

3. Which factors influence the choice of method of contraception by these migrant female head porters?

4. What factors disincentivise contraceptives use among kayayei in Ghana?

\section{Literature Review}

\subsection{Migration, Kayayei and Health Wellbeing}

Migration is a significant driver of social change. As people seek to escape environmental, social, political, cultural, and economic threats in peripheral regions or are attracted by opportunities in core regions, new family structure, social relationship cultures, livelihoods and human wellbeing concerns emerge (Amoako-Mensah, 2019; Anlimachie, 2020; Adjei, 2020; Bakewell \& Haas, 2007; Castles \& Miller, 1993). Globally, the rise in female migration has serious implications for the health and wellbeing of children and families (Adepoju, 2010; Castles \& Miller, 1993).

In Ghana, the migration of active females from the rural areas and the northern regions to the cities such as Kumasi and Accra with the hope of escaping poverty and obnoxious cultural practices like female genital mutilation, forced and child marriages are still persistent despite government efforts to eliminate these cultural injustices (Agyei et al., 2016 Fentiman \& Bundy 1999). This has led to the feminization of some urban unskilled labour and jobs like head porting, involving carrying of goods from the market centres to people's cars at lorry stations or to their client's homes (Awumbila \& Ardayfio-Schandorf, 2008). According to Yeboah et al. (2016), female head porterage has directly resulted from the rural to urban feminised flow of labour. In overcrowded, poorly planned Ghanaian cities the means of transporting light merchandise from market centres to bus stations have primarily been head 
porterage. Agarwal et al. (1997) observed that one of the commonest minimal jobs for young women in Ghanaian cities was head porterage.

Head porting has been a traditional means of carting agricultural produce, firewood and water domestically, mostly done by African women and children. Women in Africa have long been known for transporting agricultural produce by way of the head for both family consumption and to the local market. Notwithstanding the introduction of advanced and intermediate means of transport like a tricycle, bicycle motorbike and taxi, head porting is still common in Africa as it provides the most flexible and a cheaper means of carting light loads door-to-door (Baah-Ennumh \& Adom-Asamoah, 2012). According to Baah-Ennumh and Adom-Asamoah (2012), the poorly organised settlement and transportation systems contribute to traffic congestion in the central business district of Ghanaian cities fuelled by the phenomenon of head porting business. Head porting in turn is serving as a pull factor attracting young girls from the rural areas of Ghana into the cities.

Kuyini et al. (2020) investigated the nexus between female migration, kayayei and health wellbeing and found that geolocation development inequality and family issues promote migration of young females from the rural to urban areas in Ghana. The study identified some adverse effects of such migration patterns on the quality of accessing health services by the young female immigrants. The study advocated for more consideration about the implications of such large internal migration of females on national sustainability.

Lattof (2018) conducted a research study into the care-seeking behaviours of female migrants in Accra-Ghana and found that financial barriers limited kayayei from seeking healthcare. Lattof argued that, given that rural-urban migration continues to increase, health systems need to recognise the varied needs of migrants to reach them with accessible and affordable quality health services across domestic borders.

\subsection{Contraceptives Use}

There are two broad classifications of contraceptive methods; modern and traditional methods (Bledsoe et al., 1994). The modern contraceptive method is, "a product or medical procedure that interferes with the reproduction from acts of sexual intercourse" (Hatcher, 2007, p.23). The term 'modernity' tends to mean using current techniques, ideas, and equipment. This appears misleading and limited since the use of family planning predates the ordinary era (World Health Organization-WHO, 2010). According to Hubacher and Trussell (2007), the classification of family planning methods into modern and traditional is for easy categorisation to facilitate people's knowledge and the choices for the appropriate methods. Contraceptives have been also classified according to features such as effectiveness, reversibility, being hormonal, mode of action among others. Clear information from family planning providers is essential to help and guide women in choosing the best contraceptive method (WHO, 2010).

The USA Food and Drug Administration (FDA) approved the use of norethynodrel, synthetic progesterone, as an oral contraceptive for women in 1960 (Angrist et al., 1992) and the 'The Pill' manufactured by 'Enovid' became the greatest miracle drug. Since then, oral contraceptives have become very popular globally. Some 18 million women in the USA and 81,000 between the ages 15-49 use the pill every year (Asbell \& Bernard, 1995; Rosenberg et al., 1995). A survey study among women within the ages of 15-25 years in Latin America and the Caribbean found that the rate of contraceptive intake during earliest sexual contact ranged as 4\% in Quito, 43\% in Jamaica as compared with 1.5\% in Ghana (Harper, 1988). Studies show that 8 out of 100 women would get pregnant if each had a single act of unprotected sexual intercourse in the second or third week of the menstrual cycle and that 
oral contraceptives use prevents between $75 \%$ to $85 \%$ of the unexpected pregnancies, and it is higher among more educated women (ACOG 2002; Barfai, 2000; Creinin, 1997; Glasier, 1997; Trussell et al., 1994; WHO, 1998).

One of the factors that account for people's cold feet in the use of contraceptives has a link to their side effects. The use of oral contraceptives can affect the genital delay in ovulation, causing pain to some women (Brucker \& Lipford, 1995; DeJonge, 1998). According to other studies, during ovulation, ECPs use can lead to a short yellowish mass of progesterone secreting endocrine tissue that forms immediately after ovulation from the ruptured Graafian follicle in women's ovaries (corpus luteum). The use of combined oral contraceptive (COC) can also come with nausea and vomiting. About $19 \%$ of COC and $6 \%$ of Progestogen-only Pills (POP) users vomit during usage (Barfai, 2000; Glasier, 1997; Ho \& Kwan, 1993; Trussell et al., 2001). Users of COC and POP may experience dizziness, breast tenderness, headache, and fatigue. Also, bleeding irregularity may occur in the cycle during which ECPs are used (ACOG, 2002; Glasier, 1997).

Access to information and knowledge about contraception is the first step to stimulating the use of contraceptives. The extent of awareness and sensitisation varies considerably from one geographical area to another influencing the variations in contraceptive use across geolocations and socioeconomic classes (Kongnyuy et al., 2007). Ghana Demographic Health Survey-GDHS (2003) operationally defines knowledge of family planning as being aware of a particular method, its uses and effects. Socioeconomic status also influences contraceptive use. According to Ghana Demographic Health Survey -GDHS (2014) 99\% of females between the ages of 15-49 know at least one contraceptive strategy in the Kumasi Metropolis (Ghana Statistical Service \& Ghana Health Service, 2015). Addai (1999) and Ahenkan's (2017 studies on Ghana found that social demographic features and economic and cultural factors impact the acceptability, choice, and utilization of contraceptives. Obasohan's (2015) study in Nigeria also found that religion and culture influences utilisation among Nigerians.

Community participation is another determinant of contraceptive use among women (Eliason et al., 2013). A survey study involving 4300 women participants, found that, even though a combination of community effort increased awareness, knowledge and acceptance of contraceptives, there was, however, no significant difference in the proportion of women who were using contraceptives after one year of evaluating the study (Depuur et al., 2002). This finding suggests that increasing coverage for family planning services does not necessarily result in usage and that a missing ingredient, as yet unknown, is required to achieve that. In Ghana, there have been active involvements in other Non-Governmental Organizations (NGOs) complementing the government to rally local community involvement in reproductive health education (Dalaba et al., 2016).

Community culture and family relationships also influence contraceptive use (Cheng 2011; Eliason et al. 2013). Cheng's (2011) study provided evidence that family and social networks are also important factors that influence contraceptive use. The desire of the individual to learn from friends can influence contraceptives, just as the advice and support given by families (Aransiola et al., 2014; Cheng, 2011). In Africa, the increasing migration of economically active young women from rural areas to cities weakens family ties and, thus, emotional support from the traditional extended family system. Migration increases single and absentee parenting and dwindles family support for reproductive wellbeing for girls (Swadener et al., 1997). 
Additionally, research literature in Africa suggests that some traditional socio-cultural beliefs, religion, male-dominant cultural setting, and culturally induced-gender roles impact contraceptive use among women in Africa (Chipeta et al. 2010). The quest for high fertility expectancy from families to continue family lineage and to support family farming work encourage polygamy and, hence, high fertility rate and family size (Ezeh,1997). Also, the male-dominated culture in Africa requires that men have the final say in the home, including the female partners' reproductive health (Tumlinson et al., (2013). Culturally, there is a social stigma associated with women's infertility and, therefore, contraceptive usage to delay birth can induce a negative perception of barrenness in local communities (Nukunya, 2016; Sedgh et al., 2007). Prata et al. 's (2017) study on Nigeria identified partners' support for family planning as a key factor to contraceptive choice and usage. Similarly, Tumlinson et al.'s (2013) study in Angola found partners' support and communication influenced female contraceptives usage in Angola.

Livelihoods and housing impact contraceptives use in Africa. According to Anarfi et al. (2003) migrant females engaging in head porting business in Ghanaian cities have few opportunities, good housing, and time to take good care of their health wellbeing, hence have low contraceptive utilization. On the contrary, women from high socioeconomic status in Ghana tend to subscribe to contraceptive use (GSS, 2015). Adanu et al. (2009) found that women in formal employment are probable to use family planning more than those who are self-employed, especially in cities like Kumasi. There is a paucity of literature in Ghana on the links between poverty and contraceptive use, nor can it predict specific contraceptive method choice (Foster et al., 2004; Frost et al., 2007; Frost \& Darroch, 2008; Upson et al., 2010). A study conducted by Palamuleni (2013) showed that head porters who worked outside their home are more likely to use contraceptives to prevent unintended pregnancy and contracting STIs than those who are housewives.

The research literature also identified age, marital status, and type of marriage as an important set of demographic factors that impact contraceptives use globally. The age of women curvilinearly affects contraceptive use, decreasing usage from a more youthful to an older age. In Africa for example, sexually energetic single ladies are more likely to use contraceptives than (Cheng, 2011, Njogu, 1991; Sedgh et al., 2007).

\section{Methodology}

The study was theoretically situated within Bourdieu's socio-cultural theory of habitus. Bourdieu's (1986) habitus conception articulates the regularities of social behaviours within a given social structure and the interactions influenced by individuals' internal set of dispositions and immersed cultural settings which, together, shape the individuals' beliefs, actions and practices. Bourdieu made a dualisation or distinction between primary and secondary habitus. Primary habitus articulates the effect of individuals' early years learning and inculcated cultures on later years' behaviours. It thus elevates the significance of home background on individual actions. The secondary habitus is what individuals learn in later years of life, highlighting the role of youthful friends and social institutions on individuals' behaviours (Bourdieu, 1986, 1998). Whereas Croce (2015) criticised Bourdieu's habitus as being overly deterministic. Mills, 2008), a Bourduie analyst, comes with the defence that Bourdieu's habitus also incorporates a possibilism or transformation stance by recognising individuals' voluntary role to recreate habitus as evident in Bourdieu's secondary habitus conception.

The study, therefore, proceeded an amalgam of social constructivists and positivists approaches to knowledge construction by arguing that objective social knowledge must be 
based on hardcore variable evidence of regularity in social behaviour complemented by aggregation of subjective interpretations of individuals' experiences situated within a broader pattern of a given habitus, These approaches elicit generative knowledge to improve social life (Burrell \& Gareth, 1992)

Therefore the study utilised a mixed-method design. It concurrently collected and triangulated both quantitative and qualitative data(Creswell, 2021; Creswell \& Plano Clark, 2011). The quantitative design adopted a survey based on close-ended questionnaires elicited from structured responses to questionnaires from 121 kayeyeis (young female migrant head porters). The qualitative design using focus group discussion (FGD) and individual interviews elicited in-depth information to illuminate the quantitative data from the survey (Carson, 2005). Four different focus group discussions (11 per group) were held with the participating migrant female porters clustered across four main market centres in Kumasi. Additionally, four (4) individuals including pharmacy and chemists shop attendants and a drug peddler operating in these market centres, were also interviewed.

The Statistical Package for the Social Science (SPSS) was used to analyse the survey data quantitatively, and results displayed in distribution tables and charts. Descriptive coding was inductively used to analyse the qualitative data allowing key themes to emerge to explain the quantitative data.

The study site was the Kumasi Metropolis, Ghana, with a population of about 2 million (Ghana Statistical Service[GSS] 2021). Females constitute the majority (56\%) of the population (GSS, 2014; 2021). The productive age group within 15-64 years constitutes 63\% of the total population in the Kumasi Metropolis. The total population of the migrants represent more than half ( $54 \%$ ) of the total population. The migrant population with roots from the three northern parts of Ghana accounts for about $10 \%$ of the population in Kumasi Metropolis. The metropolis has 136 health centres delivering healthcare to the residents.

The accessible population for this study was migrant women. The targeted population were kayayei [ migrant females engaging in head porterage business] who were sexually active in the Kumasi metropolis. A total of 125 participants were selected from the study using a multi-stage sampling technique: purposive non-probability sampling technique and simple random sampling techniques were combined. Purposive sampling was used to identify respondents that meet the criteria for the study (migrant female head porters) specifically those who are sexually active (between the ages of $15-49$ years). The procedures for the data collection were the use of a questionnaire administered to 121 respondents (young migrant females head porters) and a further four different focus group discussions involving 44 participants drawn from the 121 kayayei who already participated in the survey. These were complemented by three individual interviews with a pharmacy, chemist shop attendant and a drug peddler from whom the respondents (kayayei) mostly access their contraceptives.

\section{Results}

\subsection{Demographic Characteristics of Respondents}

Table 1 presents the demographic characteristics of respondents, the knowledge base, pattern and usage of contraceptives, factors influencing contraceptive use, barriers, and effects of using contraceptives. The demographic characteristics include age, marital status, level of education, tribe, religion, number of children and daily income 
Table 1: Demographic Characteristics of Participants- Migrant female head porters

\begin{tabular}{|c|c|c|}
\hline Variables & Frequency & Percentage (\%) \\
\hline \multicolumn{3}{|l|}{ Age } \\
\hline 25 and below & 82 & 67.8 \\
\hline $26-33$ & 23 & 19.0 \\
\hline $34-49$ & 16 & 13.2 \\
\hline Total & 121 & 100 \\
\hline Marital Status & Frequency & Percentage (\%) \\
\hline Never Married & 54 & 44.6 \\
\hline Married & 50 & 41.3 \\
\hline Divorced & 3 & 2.5 \\
\hline Separated & 14 & 11.6 \\
\hline Total & 121 & 100 \\
\hline Level of Education & Frequency & Percentage (\%) \\
\hline Never been to school & 67 & 55.4 \\
\hline Primary & 49 & 40.5 \\
\hline Secondary & 5 & 4.1 \\
\hline Total & 121 & 100 \\
\hline Tribe & Frequency & Percentage (\%) \\
\hline Akan & 2 & 1.7 \\
\hline Ewe & 2 & 1.7 \\
\hline Dagomba & 90 & 74.4 \\
\hline Mamprusi & 27 & 22.3 \\
\hline Total & 121 & 100 \\
\hline Religion & Frequency & Percentage (\%) \\
\hline Christian & 12 & 9.9 \\
\hline Muslim & 107 & 88.4 \\
\hline Traditional & 2 & 1.7 \\
\hline Total & 121 & 100 \\
\hline Number of children & Frequency & Percentage $(\%)$ \\
\hline $1-3$ & 57 & 71.3 \\
\hline $4-6$ & 19 & 23.8 \\
\hline $7-9$ & 4 & 4.9 \\
\hline Total & 80 & 100 \\
\hline Daily Income (GH $\phi)$ & Frequency & Percentage (\%) \\
\hline $10-29$ & 76 & 62.8 \\
\hline 30.49 & 32 & 26.4 \\
\hline $50-69$ & 8 & 6.6 \\
\hline 70 and above & 5 & 4.2 \\
\hline Total & 121 & 100 \\
\hline
\end{tabular}

Source: Field Survey, 2018.

The majority of the respondents $(68 \%)$ were below 25 years and a few $(13 \%)$ were within the 34-49 years age cohort. This shows that most of the participating migrant young female head porters were younger, as also found by Anarfi et al. (2003). Out of the 121 respondents, $45 \%$ of the female migrant head porters had never married. Some $42 \%$ were married but were not with their husbands in the city, the rest had either divorced or separated from their partners, or were not sure whether their polygamous husbands still considered them as wives, having migrated to the city. 
On the level of education, as many as 67 of the respondents have never been to school while 49 of them got to the primary level and only five of them got to the secondary school level. This finding corroborated other studies(Amoako-Mensah et al., 2019; Anlimachie, 2016, 2019; Anlimachie \& Avoada, 2020) in Ghana that rural-urban migration is one of the fallouts from poor education outcomes and rural-urban inequality in educational opportunities in Ghana, pushing young people from the rural to urban areas in Ghana in search of nonexistent jobs as their acquired skills do not much with urban jobs, forcing them into menial work and social vices for economic survival.

Some 88 of the respondents were Muslim and 10\% were Christians, pointing to the fact that religion might play a role in their contraceptive use. Participants were in the low-income bracket, earning an average daily income of less than GH30 or USD 5 while they require at least GH 30 a day for individual feeding, excluding their child(ren) if any.

\subsection{Knowledge Base}

Figure 1 presents the sources of information about contraceptives for participants. The results show that greater proportions of the sources of information were from friends, health facilities/professionals and the mass media( mostly radio). About 46\% of the respondents received their information about contraceptives from city-based friends and partners, some 18\% had accessed their information from the mass media and public campaigns, while $14 \%$ received their source of information from health professionals. However, family, basic schools and religious groups accounted for only $22 \%$ of the sources of information on contraceptives of the respondents. The role of the mass media affirmed a study conducted by Udry et al. (1972) in the US that found that the mass media education on reproductive health increased the awareness of contraceptive use in the USA. The insignificant contribution of respondents family, religious group and Basic Schools to contraceptive use information suggest that the primary habitus' impact of contraceptive use decisions in rural Ghana is limited compared to the secondary habitus influencers like city friends, the media and health professionals, a sign that urban setting and lifestyle could significantly shape the perceptions of migrant young ladies in Ghanaian cities about contraceptives than their inculcated early years experiences.

\section{Sources of information on contracetive use among Kayayei, Kumasi Metroplolis, Ghana}

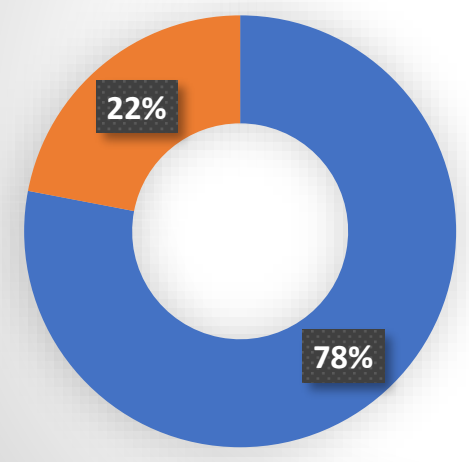

- Secondary habitus[City-based friends and sexual partners, the mass media, public campaigs and health facilities/professionals]

- Primary habitus[ family, Basic school and relious group]

Figure 1: Sources of information on contracetive use among Kayayei, Kumasi Metroplolis, Ghana

Source: Field Survey, 2018 
Table 2 below shows the perceived use of contraceptives by the respondents. A greater number, about $44(36.4 \%)$, of the respondents indicated that contraceptives are used for protection. This shows that a lot of the head porters knew the use of contraceptives in general. A 1993study conducted in Sub-Saharan Africa by the National Research Council showed that women who are employed and have some levels of education are most likely to use contraceptives more than those who are unemployed and uneducated

Table 2: Perceived uses of contraceptives by respondents

\begin{tabular}{|l|l|l|}
\hline Variables & Frequency & Percentage (\%) \\
\hline Birth control & 18 & 15.8 \\
\hline Family Planning & 16 & 14.0 \\
\hline Prevent Pregnancy & 21 & 18.4 \\
\hline Protection & 44 & 38.6 \\
\hline Protection from STIs & 3 & 2.6 \\
\hline Sex & 12 & 1.8 \\
\hline Total & 114 & 100 \\
\hline
\end{tabular}

Source: Field Survey, 2018

As depicted in Figure 2 and Table 3, the respondents demonstrate high knowledge of the various contraceptives. The most popular contraceptive among respondents was condoms $(47 \%)$ followed by intrauterine devices (39\%), and oral contraceptives (33\%). The least known was the withdrawal method. Also, in terms of usage, most of the respondents, about $36 \%$, use intrauterine device, followed by condoms, $33 \%$ of respondents, and oral contraceptives, $28 \%$ of respondents. The majority $(81.0 \%)$ of the respondents were using contraceptives. Some $(38.8 \%)$ used intrauterine device, followed by oral contraceptives 31 , $31.6 \%$ ) and the least (29 representing $29.6 \%$ ) was the condom.

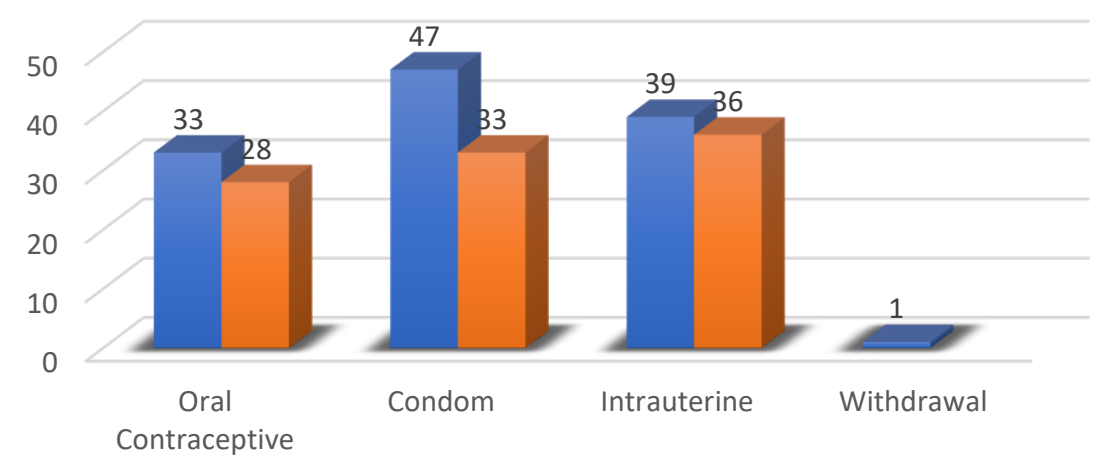

What they know(Freq.) What they have used before(Freq.)

Figure 2: The type of contraceptive known by respondents and those they use Source: Field Survey Data, 2018

Table 3: The pattern and usage of contraceptives by respondents

\begin{tabular}{|l|l|l|}
\hline Questions & Frequency & Percentage (\%) \\
\hline Do you use any contraceptive & 81.0 \\
\hline Yes & 98 & 19.0 \\
\hline No & 23 & 100 \\
\hline Total & 121 & 31.6 \\
\hline Which of the contraceptive did you use? & 31 & \\
\hline
\end{tabular}




\begin{tabular}{|c|c|c|}
\hline Condom & 29 & 29.6 \\
\hline IUD & 38 & 38.8 \\
\hline Total & 98 & 100 \\
\hline \multicolumn{3}{|c|}{ Where did you get it from? } \\
\hline Hospital & 45 & 45.9 \\
\hline Purchase & 51 & 52.0 \\
\hline Friends & 2 & 2.0 \\
\hline Total & 98 & 100 \\
\hline \multicolumn{3}{|c|}{ If you purchased, where did you purchase it? } \\
\hline Drug store & 19 & 37.3 \\
\hline Drug peddlers & 34 & 62.7 \\
\hline Total & 51 & 100 \\
\hline \multicolumn{3}{|c|}{ How long have you been using it? (years) } \\
\hline $1-2$ & 64 & 69.6 \\
\hline $3-5$ & 20 & 21.7 \\
\hline $6-8$ & 2 & 2.2 \\
\hline 9 and above & 6 & 6.5 \\
\hline Total & 92 & 100 \\
\hline
\end{tabular}

Source: Field Survey Data, 2018

From the focus group discussion, the condom was the commonest in terms of availability and ease of access, but intrauterine device (IUD) was preferred because it was done for free for the respondents. According to d'Arcangues (2007), the IUD remains the most widely used method of contraception in the world today, particularly in emerging countries rather than developed countries.

Most respondents prefer buying contraceptives from drug peddlers because of convenience, such as cheaper cost of contraceptives from this source, confidentiality, accessibility, and demand information about a particular contraceptive. This is reflected in the focus group discussion and interview as follows:

I do not buy my pill from the drug store because I'm shy to go there -respondent (FGD3 Asafo).

Most of the head potters come to buy pills from me, when they come, they can interact with me and I give them the quantity they want (a drug peddler),

I see only a few of the female head porters coming to buy contraceptives (pill) but some of their guys come to buy condoms (pharmacist).

The respondents were also asked where they get these contraceptives from. The majority, $52.0 \%$ of them, purchased it, $46 \%$ got it from the hospital and the rest $(2 \%)$ obtained it from friends. Of those who purchased it, 63\% got it from drug peddlers and 37\% from the drug store. The respondents were further asked how long they had been using these contraceptives. Out of the $92 \%$ of respondents who responded to this question, the majority $(70 \%)$ had used it for at least two years, $21.7 \%$ had used it for between three to five years and $2 \%$ and $7 \%$ for between six to eight years and above nine years, respectively.

Figure 3 below shows that most of the respondents' use of the IUD is based on reasons such as it is free, secure, husband's choice, and boyfriend's influence. According to an interview at the Pampaso Children's hospital, a nurse indicated that the IUD was done free of charge for the head porters last year. The service was rendered based on a collaborative effort of the Street Children Project and the hospital. 


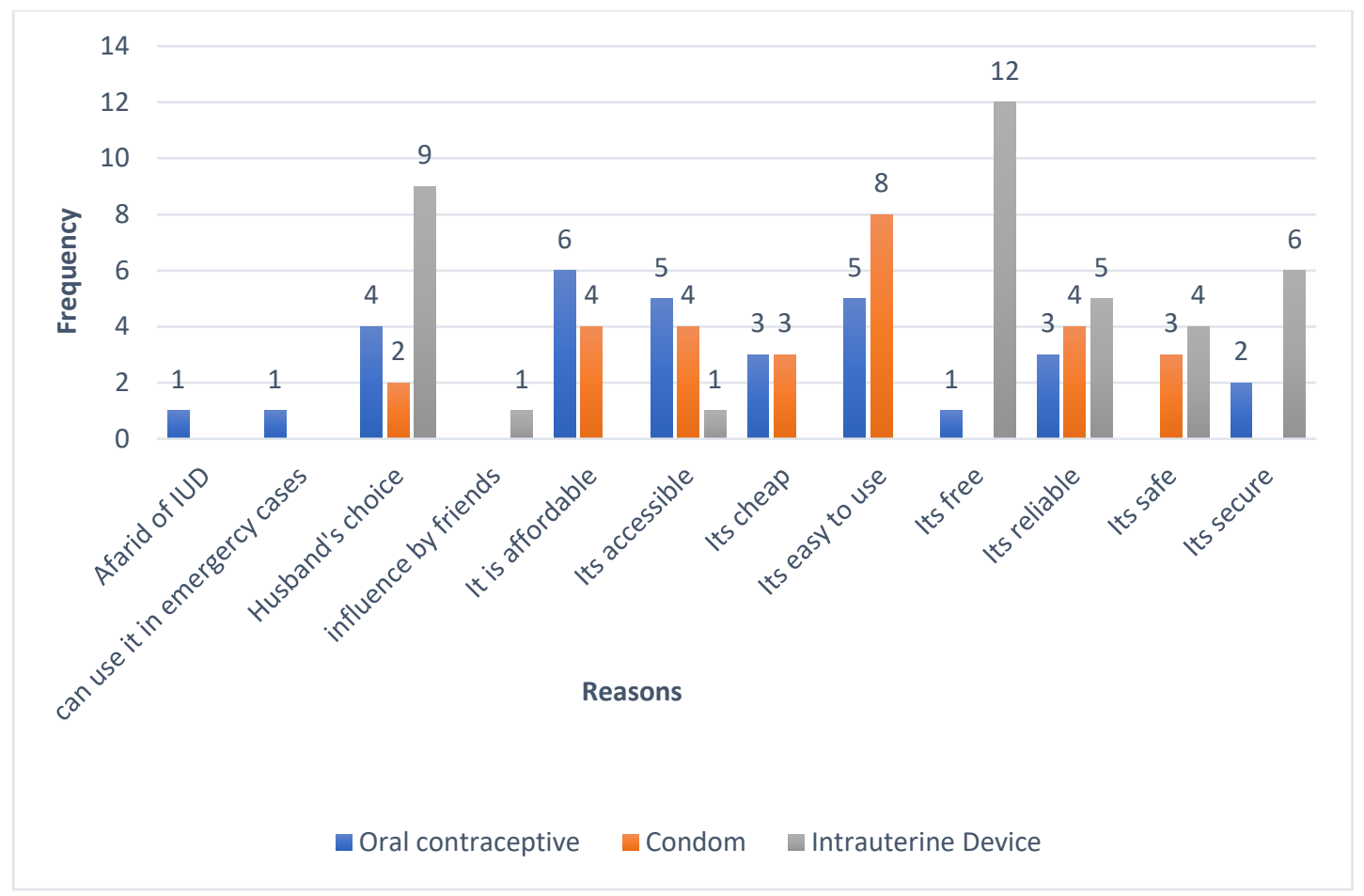

Figure 3: The reasons for the choice of a particular contraceptive

Source: Field Survey Data, 2018

\subsection{Factors Influencing Contraceptive Use}

Table 4 below presents data analysis on the factors that influenced contraceptive use decisions of the participating kayayei. It begins with exploring respondents' views on culture and religion [representing participants' primary habitus] and urban life and urban male sexual partners [representing participants' secondary habitus) as preselected factors that could influence kayayei contraceptives utilisation choice. The data in Table 4 show that participants' inculcated home culture and religion have a fairly significant impact (35\%) on contraceptive use while domiciled in their home communities. But, as they migrate to the cities, the home culture influence gave way to the influence of city lifestyle, especially their city sexual partners' support $(80 \%)$ for contraceptive use.

The results show that the partner's approval was the single most significant factor that influences the uptake of contraceptives among migrant female head porters in the Kumasi metropolis. Women who never discussed contraception with their partners were $90 \%$ less likely to use contraceptives. An earlier study in southern Ghana has also testified that spousal consensus was still pertinent in contraceptive uptake among women (Adongo et al., 2013). 
Table 4: Cultural factors that influence the use of contraceptives

\begin{tabular}{|l|l|l|}
\hline Statement & Responses & $\%$ \\
\hline \multirow{2}{*}{$\begin{array}{l}\text { My home culture/ religion is against } \\
\text { the use of contraceptives }\end{array}$} & Yes & 40 \\
\cline { 2 - 3 } & No & 60 \\
\hline $\begin{array}{l}\text { My city partner supports } \\
\text { contraceptives use }\end{array}$ & Yes & 73.5 \\
\cline { 2 - 3 } & No & 26.5 \\
\hline \multirow{2}{*}{$\begin{array}{l}\text { contraceptive use decision in my } \\
\text { current city (migrant) status }\end{array}$} & My male sexual partner & $80 \%$ \\
\cline { 2 - 3 } & $\begin{array}{l}\text { My inculcated home culture \& } \\
\text { religion }\end{array}$ & $18 \%$ \\
\cline { 2 - 3 } & None of the above & $2 \%$ \\
\hline
\end{tabular}

Source: Field Survey Data, 2018

The FGD elicited deeper explanations that participants who never discussed contraceptive intake with their partners face challenges of mistrust and breakdown of relationships. These were expressed as follows:

When my sexual partner found out that I was using a contraceptive (IUD) without his notice, his trust, care and love for me weaned, He told me I don't respect him and that I am not to be trusted anymore and accused me of having extra affairs (FGD 1, Central market)

When I decided to go in for the IUD because it is free of charge and last longer, I have to convince my male partner before be reluctantly gave his consent. You know our culture when you do this thing at their (male sexual partners) blind side they think you are cheating on them (FGD 2, Kejetia Market)

Further, Table 5 below presents respondents' responses on the perceived barriers to contraceptive use. Most respondents (66\%) disagreed that the issues of affordability, accessibility, religious beliefs, culture, and perceived health risk have a significant influence on their use of contraceptives. This is because family planning methods in health facilities in Ghana are virtually free and the cost of contraceptive is very low as they are heavily subsidized. However, $44 \%$ of the responses were either neutral or negative, suggesting that the above factors may still serve as stumbling blocks to contraceptive utilisation among respondents, especially the issue with perceived health risks on contraceptives' link to the low education level of the respondents, as well as the issues relating to affordability linked to the low-income levels of the respondents. The population to health professionals of the ratio of 2.65 per 1000 and health facilities to population ratio of 1 per 11,7000 population in Ghana also point to accessibility challenges.

Table 5: The barriers to the use of contraceptives by respondents

\begin{tabular}{|l|l|l|l|l|l|l|}
\hline Statement & $\begin{array}{l}\text { Strongly } \\
\text { Disagree (\%) }\end{array}$ & $\begin{array}{l}\text { Disagree } \\
(\%)\end{array}$ & $\begin{array}{l}\text { Neutral } \\
(\%)\end{array}$ & Agree (\%) & $\begin{array}{l}\text { Strongly } \\
\text { Agree (\%) }\end{array}$ & Total \\
\hline $\begin{array}{l}\text { I do not use contraceptives } \\
\text { because it is not affordable }\end{array}$ & 23.3 & 46.3 & 23.1 & 5.8 & 2.5 & 100 \\
\hline $\begin{array}{l}\text { I do not use contraceptives } \\
\text { because it is not accessible }\end{array}$ & 30.6 & 44.6 & 16.5 & 5.8 & 2.8 & 100 \\
\hline $\begin{array}{l}\text { I do not use contraceptives } \\
\text { because my religion forbids }\end{array}$ & 23.1 & 38.8 & 25.6 & 6.6 & 5.8 & 100 \\
\hline
\end{tabular}




\begin{tabular}{|l|l|l|l|l|l|l|}
\hline it & & & & & & \\
\hline $\begin{array}{l}\text { I do not use contraceptives } \\
\text { because my culture is } \\
\text { against it }\end{array}$ & 26.4 & 39.7 & 22.3 & 5.0 & 6.6 & 100 \\
\hline $\begin{array}{l}\text { I do not use contraceptives } \\
\text { because of perceived health } \\
\text { risk }\end{array}$ & 13.2 & 43.0 & 29.8 & 7.4 & 6.6 & 100 \\
\hline $\begin{array}{l}\text { Cumulative weighted } \\
\text { average }\end{array}$ & $\mathbf{2 3}$ & $\mathbf{4 3}$ & $\mathbf{2 3}$ & $\mathbf{6}$ & $\mathbf{5}$ & $\mathbf{1 0 0}$ \\
\hline
\end{tabular}

Source: Field Survey Data, 2018

The qualitative data elicited partners' approval and reliability concerns as key determinants of contraceptive use among the migrant young women compared to their home culture and religion. A participant explained during one of the FGDs that:

Previously, I was using condoms and pills but now I'm using IUD because it is reliable and free too (FGD 2 Central market).

My culture and religion do not influence me on the use of contraceptives because my family and home community members are far away from me. I just need approval from my partner (FGD1 Kejetia)

Also, respondents' views on the side effects of contraceptives use were explored to find out if it impacted their contraceptive use decision or choices. As detailed in Table 6 below, the respondents identified inconveniences during menstruation (43\%), increase in weight $(31 \%)$ and anxieties about future infertility $(22 \%)$ as some of the reasons and misconceptions that deter them from full utilisation of contraceptives or family planning methods.

Table 6: Effects to the use of contraceptives by respondents

\begin{tabular}{|l|l|l|}
\hline Perceived Effect & Frequency & Percentage (\%) \\
\hline Menstruation & 52 & 43.0 \\
\hline Weight gain & 31 & 25.6 \\
\hline Future infertility & 22 & 18.2 \\
\hline Others & 16 & 13.2 \\
\hline Total & 121 & 100 \\
\hline
\end{tabular}

Source: Field Survey Dats, 2018

Respodents' views on why their male sexual partners would not support their contraceptive use decision as captured in Figure 4 below included side effects like mild sickness, as well as the misconceptions about future miscarriages, aside from infertility. Also, their male sexual partners' disapproval relating to the fact that the use of contraceptive impedes sexual also emerged from the qualitative data as the reasons for some level of cold feet to contraceptive use among the study research group. 


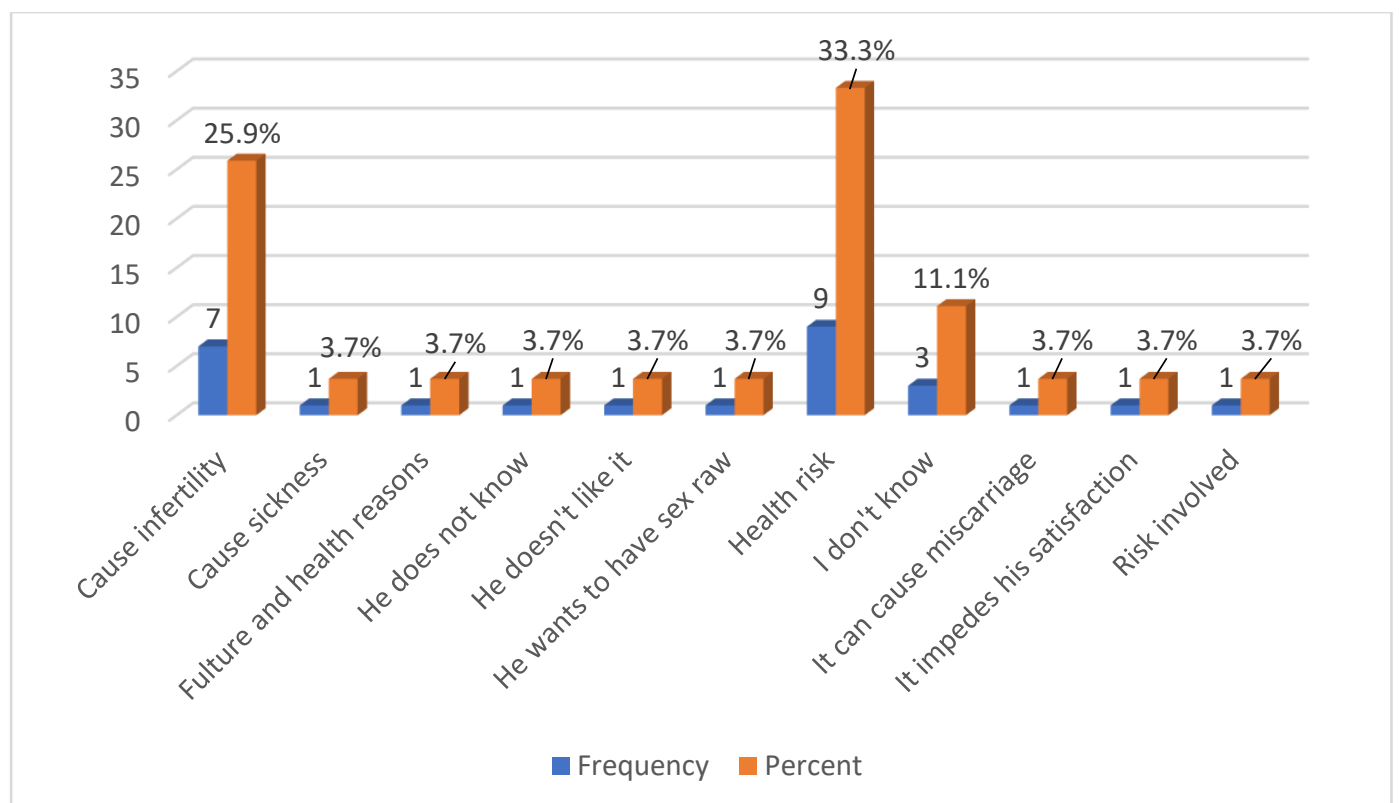

Figure 4: Respondents' views on why their male sextual partners did not support contraceptives use

Source: Focus Group and Interview Data 2018

In sharing her experiences of contraceptive use, a participant explained during one of the FGDs that:

I accidentally bad my first child since I wasn't using contraceptives because I was misinformed by my family and friends in my village that it can cause infertility. But with the burdle of urban life, I have no alternative but to use it, since any pregnancy now would make things difficult for me. There is no family member here to support me if I give birth here (in the city]. I also need to protect myself from sexually transmitted diseases. Since a started using the contraceptives, I have gained some weight. I sometimes also experience some inconveniences I sometimes stop it for a while, but I go for it again, it becomes critical. I believe that the inconveniences are worth the protection (FGD 3 Asafo market)

From the above data, perceived and real side effects and misconceptions associated with contraceptives impact the level of utilisation among the study group. The data also show that the participating young migrant ladies engaging in head porting business in the cities are more conscious to use contraceptives than when they were in their home rural communities. This is due to comparatively better and more accessible information and reproductive healthcare services in the city. Also, the high cost of city life and the absence of the traditional extended family collective support in the cities forced them to rethink the need for birth control measures to reduce their experiences of urban economic hardship.

The data on the factors influencing contraceptive use among the study female migrant in Kumasi metropolis of Ghana suggest that socio-culturally male sexual partners have more influence on the migrant young ladies' contraceptive use choices compared to their enmeshed home culture and religion. This finding contradicts studies (Addai, 1999; Chipeta et al., 2010; Obasohan, 2015) in Africa that have identified culture and religion as significant determinants on contraceptive use. In the case of the study participants, having migrated to the cities, the young ladies were no longer under the strict cultural and religious norms and scrutiny of their home and rural communities. The finding also runs counter to Bourdieu's (1986) primary habitus conception that the place and culture in which individuals are nurtured in the early years have a significant influence on their later life actions and can recreate individual habitus and shape cultural beliefs. In the case of the study participants, 
the new urban individualistic lifestyle compared to their rural homes' collective way of living bring them into the realities of the need for subscribing to birth control measure to escape from the inconvenience of nursing a child with their kayayei business, coupled with their poor housing conditions. Also, the high cost of living in the cities, coupled with the freedom from family and home culture scrutiny, forced them into new sexual partners in the cities in exchange for financial upkeeps and shelter. In the process, new cultures and significant social others are formed to shape their inculcated home cultural norms and religious positionality on contraceptive use. This resonates with Mills (2008) and Croce's (2015), Bourduie analysis view that habitus is not overly deterministic and individuals' voluntary roles and secondary habitus recreate new beliefs and social practices.

\section{Conclusions}

Results show that about $96.7 \%$ of the migrant lady head porters in the Kumasi town are from the Northern part of Ghana and have migrated to the South mainly to engage in the head porting business (kayayei) to fight poverty. Most of the migrant female head porters demonstrated fair to high knowledge on contraceptives use, and utilise contraceptives as a precautionary strategy against unplanned pregnancies and sexually transmitted diseases. But the inconveniences associated with menstruation, weight gain/loss and headache emerged as some of the side effects of contraceptives that deter the young migrant women from contraceptive usage, affirming several other studies (ACOG, 2002; Brucker \& Lipford, 1995; DeJonge, 1998; Glassier, 1997).

The study found the intrauterine device (IUD) and the oral method (pills) as the most common contraceptives used among the kayayei. The study found affordability, accessibility and security as the key reasons for the choice of contraceptives by the participants. However, the most significant factor influencing the use of contraceptives among the participating migrant female head porters (kayayei) was their male sexual partners' consent. The participants opined that they required approval from their male sexual partners before they could use contraceptives in a male-dominant Ghanaian cultural setting as women who use contraceptives without their partners' approval or knowledge were tagged as infidelity persons. This finding corroborates other studies, including Tumlinson et al. (2013) and Prata et al. (2017) that partners' choices, support, and communication influences female contraceptives usage in Africa.

The findings generally showed that socio-cultural factors have significantly low effects on contraceptive use among migrant female head porters in city settings compared to when they were in their home rural communities. The newfound urban life tends to free the migrant young women from the strict home and community culture. Also, the comparatively better access to reproductive health information in the cities tends to free most of the young migrant women from misinformation, misconception and negative cultural and religious beliefs associated with contraceptive use among rural communities in Ghana. Thus making their male sexual partners the most influential group on their contraceptive use in a city setting. This finding corroborates other studies (Addai, 1999; Chipeta et al. 2010; Obasohan, 2015;) in Ghana and Nigeria that found religion and culture are crucial determinants of contraceptive use among rural communities in Africa, compared to the urban areas. Therefore, targeting kayaei and their sexual male partners within Ghanaian cities with public education, accessible reproductive health information, and affordable family planning services can improve the health reproductive health wellbeing of low-income and vulnerable women in Ghanaian cities. 
This study, therefore, recommends intensified reproductive health education and campaigns on the importance, security and usage of contraceptives among female migrants in Ghanaian cities. This is critical as this group better responds to contraceptive use in the cities than in their home rural communities. Also, education and public campaigns on contraceptive use must target males since males have the most significant influence on their female sexual partners' contraceptive use. Also, the Ministry of Health, Ghana, must deepen its interventions and strategies of making reproductive health information, family planning services and or contraceptive readily available, accessible and affordable to low-income groups.

\section{References}

Adanu, R. M. K., Seffah, J. D., Hill, A. G., Darko, R., Duda, R. B., \& Anafi, J. K. (2009). Contraceptive use by women in Accra, Ghana: results from the 2003 Accra Women's Health Survey: original research article. African Journal of Reproductive Health, 13(1), 123-133.

Addai, I. (1999). Does religion matter in contraceptive use among Ghanaian women? Review of Religious Research, 40(3), 259-277.

Adepoju, A. (2010). Migration in West Africa. Development, 46(3), 37-41.

Agarwal, S., Attah, M., Apt, N., Grieco, M., Kwakye, E. A., \& Turner, J. (1997). Bearing the weight: the kayayoo, Ghana's working girl child. International Social Work, 40(3), 245263.

Agyei, Y. A., Kumi, E., \& Yeboah, T. (2016). Is it better to be a kayayei than to be unemployed: reflecting on the role of head portering in Ghana's informal economy. Geojournal, 81(2), 293-318.

Ahenkan, V. (2017). Determinants of modern contraceptive use among migrant female head porters in Asokore-Mampong Municipality [Doctoral dissertation].

Amoako-Mensah, T., Anlimachie, A. M., Adu, B. S., \& Elorm, E. A. (2019). Out-migration and the Double Jeopardy of rurality in Ghana. An integrated approach to rural development. European Journal of Geography, 10(1), 50-67

Anarfi, J. K. (2003). The role of local herbs in the recent fertility decline in Ghana; contraceptives and abortifacients. The socio-cultural and political aspect of abortion. Westport, Connecticut: Praeger

Anlimachie, M. A. (2016). Achieving Equity in Basic Education in Ghana; Contexts and Strategies. [Masters of Philosophy Thesis, University of Oslo].

Anlimachie, M. A. (2019). Enacting Relevant Basic Education to Bridge the Rural-Urban Inequality in Ghana; The Prospects and Approaches for Investigating Rural Educational Realities. International Journal of Humanities and Social Sciences, 11(1), 42-58.

Anlimachie, M. A., \& Avoada, C. (2020). Socio-economic impact of closing the rural-urban gap in pre-tertiary education in Ghana: context and strategies. International Journal of Educational Development, $\quad$ 77(102236), 1-12. https://doi.org/10.1016/j.ijedudev.2020.10

Aransiola, J. O., Akinyemi, A. I., \& Fatusi, A. O. (2014). Women's perceptions and reflections of male partners and couple dynamics in family planning adoption in selected urban slums in Nigeria: a qualitative exploration. BMC Public Health, 14(1), 869.

Asbell, B. (1995). The Pill: A Biography of the Drug That Changed the World.

Awumbila, M., \& Ardayfio-Schandorrf, E. (2008). Gendered poverty, migration, and livelihood strategies of female porters in Accra, Ghana. Norsk Geografisk TidsskriftNorwegian Journal of Geography, 62(3), 171-179. 
Baah-Ennumh, T. Y., \& Adom-Asamoah, G. (2012). The Role of Market Women in The Informal Urban Economy in Kumasi. Journal of Science and Technology (Ghana), 32(2), $56-67$.

Bakewell, O., \& De Haas, H. (2007). African Migrations: Continuities, Discontinuities And Recent Transformations. In P. Chabal, U. Engel \& L. de Haan (Eds.), African Alternatives (pp. 95-117). Brill.

Barfai, G. (2000). Emergency Contraception in Clinical Practice: Global Perspectives.

Bonifacio, G. T. (Ed). (2012). Feminism and Migration: Cross-Cultural Engagements (vol. 1). Springer Science \& Business Media.

Bourdieu, P. (1986). The forms of capital. In J. Richardson (Ed.), Handbook of theory and research for the sociology of education (pp. 241-258). New York: Greenwood Press.

Brucker, C., \& Lipford, G.B. (1995). The human sperm acrosome reaction: physiology and Regulatory Mechanisms. An update. Human Reproductive Update, 1(1), 51-62.

Burrell, G., \& Gareth, M. (1992). Sociological Paradigms and Organisational Analysis. Part I - In Search of a Framework. Burlington, MA: Ashgate.

Carter, E., Rose, P., Sabates, R., \& Akyeampong, K. (2020). Trapped in low performance? Tracking the learning trajectory of disadvantaged girls and boys in the Complementary Basic Education programme in Ghana. International Journal of Educational Research, 100, 101541.

Creswell, J. W. (2021). Educational Research: Planning, Conducting, and Evaluating Quantitative and Qualitative Research (6th edn.). United Kingdom: Pearson Education Limited.

Creswell, J. W., \& Plano Clark, V. L. (2011). Designing and conducting mixed methods research (2nd ed.). Los Angeles: SAGE Publications.

Castles, S., \& Miller, M. J. (1993). The age of migration: International population movements in the modern world. Basingstoke: Macmillan.

Cheng, K.-W. (2011). The effect of contraceptive knowledge on fertility: The roles of mass media and social networks. Journal of Family and Economic Issues, 32(2), 257-267.

Chipeta, E. K., Chimwaza, W., \& Kalilani-Phiri, L. (2010). Contraceptive Knowledge, Beliefs and Attitudes in Rural Malawi: Misinformation, Misbeliefs and Misperceptions. Malawi Medical Journal, 22(2), 38-41.

Cleland, J., Bernstein, S., Ezeh, A., Faundes, A., \& Glasier, A. (2006). Family planning: the unfinished agenda. Lancet, 368(9549), 1810-1827.

Creinin, M. D. (1997). A Reassessment of The Efficacy of The Yuzpe Regimeno Emergency Contraception. Human Reproduction, 12(3), 496-498.

Croce, M. (2015). The Habitus and the Critique of the Present: A Wittgensteinian Reading of Bourdieu's Social Theory. Sociological Theory, 33(4), 327-346. https://doi.org/10.1177/0735275115617801

d'Arcangues, C. (2007). Worldwide use of intrauterine devices for contraception. Contraception, 75(6), S2-S7.

Dalaba, M. A., Stone, A. E., Krumholz, A. R., Oduro, A. R., Phillips, J. F., \& Adongo, P. B. (2016). A qualitative analysis of the effect of a community-based primary health care programme on reproductive preferences and contraceptive use among the KassenaNankana of northern Ghana. BMC Health Services Research, 16(1), 1-8.

Darroch, J. E., Sedgh, G., \& Ball, H. (2011). Contraceptive Technologies: Responding to Women's Needs. Guttmacher Institute.

DeJonge, C. U. (1998). An Update On Human Fertilization. Seminars in Reproductive Medicine 16(3), 209-217.

Eliason, S., Baiden, F., Quansah-Asare, G., Graham-Hayfron, Y., Bonsu, D., Phillips, J., \& Awusabo-Asare, K. (2013). Factors influencing the intention of women in rural Ghana to adopt postpartum family planning. 
Ezeh, A. C. (1997). Polygyny and Reproductive Behavior in Sub-Saharan Africa: A Contextual Analysis. Demography, 34(3), 355-368.

Fentiman, A, Hall, A., \& Bundy, D (1999). School Enrolment Patterns in Rural Ghana: A comparative study of the impact of location, gender, age and health on children's access to basic schooling. Comparative Education, 35(3), 331-349.

Foster, D. G., Bley, J., Mikanda, J., Induni, M., Arons, A., Baumrind, N., \& Stewart, F. (2004). Contraceptive Use and Risk Of Unintended Pregnancy in California. Contraception, 70(1), 31-39.

Frost, J. J., \& Darroch, J. E. (2008). Factors associated with Contraceptive Choice and Inconsistent Method Use, United States, 2004. Perspectives on Sexual and Reproductive Health, 40(2), 94-104.

Frost, J. J., Singh, S., \& Finer, L. B. (2007). Factors associated with contraceptive use and nonuse, United States, 2004. Perspectives on Sexual and Reproductive Health, 39(2), 90-99.

Ghana Statistical Service [GSS]. (2012). Population and Housing Census. 2010. Assembly Press Accra.

GSS.(2008). Ghana Demographic and Health Survey 2008.

GSS. (2012). Population Census Report. Accra. Ghana Statistical Service.

GSS, Ghana Health Service (GHS), \& ICF Macro. (2015). Ghana Demographic and Health Survey 2014: Key Indicators. Accra, Ghana.

Ghana Statistical Service [GSS]. (2021). Preliminary Report, Population and Housing Census 2021. GSS, Accra.

Glasier, A. (1997). Emergency Postcoital Contraception. New England Journal of Medicine, $337(15), 1058-1064$.

Häggström-Nordin, E., Hanson, U., \& Tyden, T. (2002). Sex behavior among high school students in Sweden: improvement in contraceptive use over time. Journal of Adolescent Health, 30, 288-295.

Hannaford, P. C. (1995). Combined oral contraceptives: do we know all their effects? Contraception, 51(6), 325-327.

Harper, C. C., Blum, M., Thiel de Bocanegra, H., Darney, P. D., Speidel, J. J., Policar, M., \& Drey, E. A. (2008). Challenges in translating evidence to practice: The provision of intrauterine contraception. Obstetrics \& Gynecology, 111, 1359-1369.

Hart, C. (1998). Doing a literature review: Releasing the social science research imagination. London, UK: Sage Publications.

Hatcher, R. A., Trussell, J., Nelson, A. L., Cates, W., Stewart, F. H., \& Kowal, D. (2007). Contraceptive Technology (19 ${ }^{\text {th }}$ ed.). New York, NY: Ardent Media, Inc.

ICF International. (2012). Measure DHS STAT compiler. http://www.statcompiler.com

IOM. (2014). Migration Initiatives 2014: Health of Migrants. IOM, Geneva.

Kongnyuy, E. J., Ngassa, P., Fomulu, N., Wiysonge, C. S., Kouam, L., \& Doh, A. S. (2007). A survey of knowledge, attitudes, and practice of emergency contraceptives among university students in Cameroon. BMC Emergency Medicine, 7(1), 7.

Kuyini, A. B., Abukari, A., Mohammed, A. K., \& Powell, H. O. (2020).Narratives of internal migration experiences, health/well-being issues among females working as headporters (Kayayei) in Ghana. International Journal of Migration, Health and Social Care, 16(4), 511-525. https://doi.org/10.1108/IJMHSC-07-2020-0068

Lattof, S. R. (2018). Health insurance and care-seeking behaviours of female migrants in Accra, Ghana. Health Policy and Planning, 33(4), 505-515.

Mills, C. (2008). Reproduction and Transformation of Inequalities in Schooling: The Transformative Potential of the Theoretical Constructs of Bourdieu. British Journal of Sociology of Education, 29(1), 79-89. http://doi.org/10.1080/01425690701737481

National Research Council. (1993). Factors affecting contraceptive use in Sub-Saharan Africa. National Academies. 
Njogu, W. (1991). Trend and determinant of contraceptive use in Kenya. Demography, 28(1), 83-99.

Nukunya, G. (2016). Tradition and Change in Ghana, An Introduction to Sociology (2 $2^{\text {nd }}$ edn). Accra, Ghana: Universities Press.

Obasohan, P. E. (2015). Religion, ethnicity and contraceptive use among reproductive age women in Nigeria. International Journal of MCH and AIDS, 3(1), 63.

Opare, J. A. (2003). Kayayei: the women head porters of Southern Ghana. Journal of Social Development in Africa, 18(2).

Palamuleni, M. E. (2013). Socio-economic and demographic factors affecting contraceptive use in Malawi: original research article. African Journal of Reproductive Health, 17(3), 91104

Population Council. (2015). Low Use and High Discontinuation of Modern Contraceptives in Pakistan: Reasons and Policy Recommendations. Islamabad, Pakistan.

Prata, N., Bell, S., Fraser, A., Carvalho, A., \& Neves, I. (2017). Partner support for family planning and modern contraceptive use in Luanda, Angola. African Journal of Reproductive Health, 21(1), 35-48

Rosenberg, M.J., Waugh, M.S., \& Long, S. (1995). Unintended pregnancies and use, misuse, and discontinuation of oral contraceptives. Journal of Reproductive Medicine, 40(5), 355360.

Sedgh, G., Hussain, R., Bankole, A., \& Singh, S. (2007). Women with an unmet need for contraception in developing countries and their reasons for not using a method. Alan Guttmacher Institute.

Swadener, E., Kabiru, M., \& Njenga, A. (1997). Does The Village Still Raise The Child? A Collaborative Study Of Changing Child-Rearing And Community Mobilization In Kenya. Early Education And Development, 8, 285-306.

Tomasevski, K. (2005). Human Rights and Poverty Reduction Girls'. education through a buman rights lens: What can be done differently, what can be made better. http://www.odi.org/sites/odi.org.uk/files/odi-assets/publications-opinionfiles/4349.pdf

Trussell, J., Ellertson, C., Stewart, F., Koenig, J., Raymond, E.G., \& Shochet, T. (2001). Emergency Contraception: A Cost-Effective Approach to Preventing Unintended Pregnancy. Seminars in Reproductive Medicine, 19(4), 323-330.

Trussell, J., Sturgen, K., Strickler, J., \& Dominik, R. (1994). Comparative contraceptive efficacy of the female condom and other barrier methods. Family Planning Perspectives, 26(2), 66-72.

Tumlinson, K., Speizer, I. S., Davis, J. T., Fotso, J. C., Kuria, P., \& Archer, L. H. (2013). Partner communication, discordant fertility goals, and contraceptive use in urban Kenya. African Journal of Reproductive Health, 17(3), 79-90.

Udry, J. R., Clark, L. T., Chase, C. L., \& Levy, M. (1972). Can mass media advertising increase contraceptive use? Family Planning Perspectives, 4(3), 37-44.

Upson, K., Reed, S. D., Prager, S. W., \& Schiff, M. A. (2010). Factors associated with contraceptive nonuse among US women ages 35-44 years at risk of unwanted pregnancy. Contraception, 81(5), 427-434.

World Health Organisation [WHO] (1998). Task Force on Postovulatory Methods of Fertility Regulation. A randomised trial of levonorgestrel versus the Yuzpe regimen of combined oral contraceptives for emergency contraception. Lancet, 353, 429-433.

WHO/UNICEF/UNFPA/World Bank. (2010), Trends in maternal mortality: 1990 to 2008. Estimates developed by WHO, UNICEF, UNFPA, and the World Bank. Geneva, World Health Organization.

WHO. (2010). Update on family planning in Sub-Saharan Africa. In Repositioning Family Planning. Guideline for Advocacy Action (pp, 1-8), Geneva, World Health Organization. 